\title{
A nanomedicine-promising approach to provide an appropriate colon-targeted drug delivery system for 5 -fluorouracil
}

This article was published in the following Dove Press journal:

International Journal of Nanomedicine

23 November 2015

Number of times this article has been viewed

\author{
Sima Singh ${ }^{1, *}$ \\ Niranjan G Kotla ${ }^{2, *}$ \\ Sonia Tomar ${ }^{3}$ \\ Balaji Maddiboyina ${ }^{4}$ \\ Thomas J Webster ${ }^{5,6}$ \\ Dinesh Sharma ${ }^{7}$ \\ Omprakash Sunnapu²
}

'Department of Pharmaceutical Sciences and Technology, Birla Institute of Technology, Mesra, Ranchi, Jharkhand, ${ }^{2}$ Technologies for the Advancement of Science, Institute for Stem Cell Biology and Regenerative Medicine, Bangalore, Karnataka, ${ }^{3}$ Department of Pharmaceutics, Ram Gopal College of Pharmacy, Rohtak, Haryana,

${ }^{4}$ Department of Pharmaceutics, Maharishi Markandeshwar University, Mullana, Ambala, Haryana, India; ${ }^{5}$ Department of Chemical Engineering, Northeastern University, Boston, MA, USA; ${ }^{6}$ Center of Excellence for Advanced Materials Research, King Abdulaziz University, Jeddah, Saudi Arabia; ${ }^{7}$ Ranbaxy Laboratory Ltd, Gurgaon, Haryana, India

*These authors contributed equally to this work
Correspondence: Thomas J Webster Department of Chemical Engineering, Northeastern University, 360 Huntington Avenue, Boston, MA 02115, USA

Tel + I 6173736585

Email th.webster@neu.edu
Abstract: Targeted drug delivery plays a significant role in disease treatment associated with the colon, affording therapeutic responses for a prolonged period of time with low side effects. Colorectal cancer is the third most common cancer in both men and women with an estimated 102,480 cases of colon cancer and 40,340 cases of rectal cancer in 2013 as reported by the American Cancer Society. In the present investigation, we developed an improved oral delivery system for existing anticancer drugs meant for colon cancer via prebiotic and probiotic approaches. The system comprises three components, namely, nanoparticles of drug coated with natural materials such as guar gum, xanthan gum (that serve as prebiotics), and probiotics. The natural gums play a dual role of protecting the drug in the gastric as well as intestinal conditions to allow its release only in the colon. In vitro results obtained from these experiments indicated the successful targeted delivery of 5-fluorouracil to the colon. Electron microscopy results demonstrated that the prepared nanoparticles were spherical in shape and $200 \mathrm{~nm}$ in size. The in vitro release data indicated that the maximum release occurs at $\mathrm{pH} 7.2$ and 7.4 with $93 \%$ of the drug released in the presence of $4 \%(\mathrm{w} / \mathrm{v})$ of rat cecal content. In vivo results conclude a practical mechanism to maintain the integrity and intactness of the intestinal/ colonic microflora, in the face of a "chemical attack" by oral colon-targeted drug delivery for colon cancer treatment.

Keywords: colon-specific drug delivery system, polymeric nanoparticles, probiotics, 5-fluorouracil

\section{Introduction}

Colon cancer is a wide-reaching health problem due to its high mortality rates. For example, in the USA, colon cancer is the third most frequently diagnosed cancer and a prominent cause of cancer death in both men and women. The American Cancer Society reported 102,480 cases of colon cancer and 40,340 cases of rectal cancer in 2013. Colon cancer accounts for over $9 \%$ of all cancer incidences. ${ }^{1}$ Over a period of many years, most of the preexisting colonic adenomas are converted into colonic cancer. ${ }^{2}$ The tumors develop as a soft polyploid mass projecting into the lumen of the colon and have a high tendency for ulceration, infection, and hemorrhage. A hard fibrous mass encircling the colon causes reduced elasticity and peristalsis, narrowing of the lumen, and obstruction. The prevalence of colon cancer in Asian countries has increased over the past few years. ${ }^{3}$ Specifically, Elizabeth and Jamel reported a statistically significant increase in the incidence of colorectal cancer rates for both males and females from 1983-1987 to 1998-2002 in developing Asian countries and selected countries in Europe and South America. ${ }^{4}$ These increases were found to be more prominent in men as compared to women. 
The site-specific delivery of drugs to the disease site of the colon is expected to reduce side effects of drugs and to increase pharmacological responses. For a controlled release system, an oral route of administration is the first choice because of the physiology of our gastrointestinal tract, which allows us to design more varied dosage forms as compared to other delivery routes. Furthermore, an oral delivery route is the most versatile and commonly employed route for systemic action due to its ease of administration, patient compliance, and flexibility in formulation. Therefore, it appears that colon-targeted dosages with an appropriate release pattern could be very useful in providing an effective therapy for colonic diseases. ${ }^{5,6}$ It is used in the treatment of colonic diseases, such as inflammatory bowel diseases, ${ }^{7}$ Crohn's diseases, ${ }^{8}$ ulcerative colitis, ${ }^{9}$ and colon cancer. ${ }^{10-12}$

To reduce the side effects and increase the efficacy, various approaches have been used for targeting drugs to the colon. These include formation of prodrugs, ${ }^{13,14}$ time-dependent delivery systems, ${ }^{15,16}$ and coating with $\mathrm{pH}$-sensitive polymers. ${ }^{17-20}$ However, as a site for drug delivery, the colon offers a near-neutral $\mathrm{pH}$, reduced digestive enzymatic activity, and a long transit time. The side effects of drugs are minimized by maximizing their local concentrations at the target site..$^{21,22}$ However, targeting the drugs to the colon is very complicated because of its location at the distal portion of the alimentary canal and due to the presence of various enzymes, a wide range of $\mathrm{pH}$ values, and hydrodynamic conditions of the gastrointestinal tract on drug release characteristics.

5-Fluorouracil (5-FU) is an anticancer drug that forms the backbone for all chemotherapeutic regimens for patients with advanced colorectal cancer. It is a fluorinated antimetabolite of the pyrimidine uracil..$^{23}$ Intravenous administration of this drug is currently in clinical use because of its erratic bioavailability after oral administration. Intravenous administration of 5-FU for colon cancer therapy produces severe systemic side effects due to its cytotoxic effects on nontumor cells. There have been a number of reports in the literature where the administration of 5-FU has been claimed to cause cytotoxic effects, including mucositis, ${ }^{24-26}$ diarrhea, ${ }^{27,28}$ alteration in normal microflora structure, ${ }^{29}$ and translocation of bacteria. ${ }^{30-32}$

Literature demonstrates that a number of researchers ${ }^{33-38}$ have formulated colon-targeted drug delivery of 5-FU using various polysaccharides to overcome the side effects caused by 5-FU. An aspect that has been largely ignored is the cytotoxic effects that 5-FU may exert on the colonic bacteria that are involved in the metabolism of these polysaccharides (chitosan, xanthan gum [XG], amylose, and guar gum [GG], etc) and the release of the drugs in the subsequent doses. Therefore, subsequent doses may not be able to release the drugs completely. ${ }^{36}$

By understanding the disturbed microbial ecology of the gastrointestinal tract by intravenous administration of 5-FU, the aim of this study was to design and deliver a combinational therapeutic treatment to mimic the function of beneficial bacteria for drug delivery. As anticipated, the main focus of this study was to develop formulations for the sitespecific delivery of 5-FU to the colon using GG and/or XG as a carrier. The problem of the compromise in the colonic bacteria will be taken care of by administering probiotics (Bifidobacterium bifidum). These probiotics will not only restore the bacterial function to normal but also help in the metabolism of the coating gums, leading to the release of the drug in the colon to exert its carcinogenic action.

\section{Materials and methods Materials}

5-FU was a gift sample from Shilpa Medicare Ltd., Raichur, Karnataka, India. Probiotics (B. bifidum, 27 billion CFU/g) was a kind gift sample from Unique Biotech Ltd., Hyderabad, Telangana, India. GG and XG were purchased from the Central Drug House, New Delhi, India. Ethyl acetate and Tween 20 were obtained from SD Fine-Chem Limited, Mumbai, Maharashtra, India.

\section{Animals}

Thirty adult Wistar albino rats (either sex) with weights ranging 230-300 g were obtained from the Institutional Animal Ethics Committee of Department of Pharmaceutical Sciences and Technology, Birla Institute of Technology. The animals were allowed to acclimatize under standard environmental conditions. The animals were housed in the animal house in groups of five animals each in clean polyacrylic cages and maintained for $12 \mathrm{~h} / \mathrm{d}$ and light cycles at an average ambient temperature of $25^{\circ} \mathrm{C} \pm 2^{\circ} \mathrm{C}$ and $60 \% \pm 10 \%$ relative humidity. The study protocol was approved by the Institutional Animal Ethics Committee of Birla Institute of Technology vide Approval Number BIT/PH/IAEC/06/2014.

\section{Preparation of nanoparticles}

An emulsion solvent evaporation technique was used to prepare polymeric nanoparticles containing the drug. The drug $(50 \mathrm{mg}$ ) and polymer (GG:XG mixture in 1:1 ratio, $200 \mathrm{mg}$ ) were dissolved in ethyl acetate $(1.6 \mathrm{~mL})$. Then, this organic dispersion was emulsified by mixing at 1,100 rpm, with a REMI Laboratory overhead stirrer provided with a three bladed paddle rotor, into an aqueous $(0.4 \mathrm{~mL})$ external 
phase containing Tween $20(0.25 \%)$ at room temperature. The organic phase was added dropwise to the aqueous phase at a constant rate. Stirring of the oil/water emulsion was continued until the ethyl acetate evaporated. The resultant dispersion was freeze dried for 48 hours.

\section{Characterization of nanoparticles}

\section{Scanning electron microscopy}

The external and internal morphologies and surface of the nanoparticles were evaluated using digital scanning electron microscopy (JSM-6100; JEOL, Tokyo, Japan). Scanning electron microscope samples were prepared by lightly sprinkling the nanoparticle powder on a double-sided adhesive tape, which was stuck on an aluminum stub. The stubs were then coated with gold using a sputter coater, and the photographs of the samples were taken at $\times 30$.

\section{Particle size analysis}

The particle size was determined using a laser diffraction particle size analyzer (Malvern Mastersizer; Malvern Instruments, Malvern, UK). Nanoparticles were suspended in the chamber of the particle size analyzer containing distilled water, and the particle size was determined using Master sizer 3000 software (Malvern Instruments Limited, Malvern, UK).

\section{Determination of drug content}

The encapsulation efficiency of the prepared nanoparticles was determined by accurately weighing an appropriate amount $(100 \mathrm{mg})$ of nanoparticle formulation dispersed in $100 \mathrm{~mL}$ of phosphate buffer saline (pH 7.4). The samples were ultrasonicated for three consecutive periods. They were left to equilibrate for 24 hours at room temperature and then centrifuged at 3,000 rpm for 15 minutes. The supernatant was diluted with phosphate buffer saline ( $\mathrm{pH}$ 7.4) and analyzed for 5 -FU by ultraviolet spectroscopy at a wavelength of $265.6 \mathrm{~nm}$. The drug content of each sample was determined in triplicate.

\section{In vitro drug release studies}

Experiments were carried out in a $200 \mathrm{~mL}$ beaker immersed in water in the jars of a dissolution test apparatus. A nanoparticle formulation of $100 \mathrm{mg}$ was added to each of the vessels (beakers) containing the dissolution medium. For the first 2 hours, the dissolution study was carried out in $150 \mathrm{~mL}$ of a $\mathrm{pH} 1.2 \mathrm{HCl}$ buffer using $100 \mathrm{rpm}$ at $37^{\circ} \mathrm{C} \pm 0.5^{\circ} \mathrm{C}$. Afterward, the $\mathrm{pH}$ of the dissolution media was adjusted to 6.8 using $50 \mathrm{~mL}$ of $\mathrm{pH} 6.8$ phosphate buffer saline and sodium hydroxide as the study continued for up to 3 hours.
Table I Treatment and doses given to animals

\begin{tabular}{llll}
\hline S no & Groups & Treatment & Dose (po) \\
\hline I & Group I & Nanoparticles of GG:XG & $8 \mathrm{mg} / \mathrm{d}$ \\
2 & Group II & 5-FU powder & $8 \mathrm{mg} / \mathrm{d}$ \\
3 & Group III & 5-FU-loaded nanoparticles & $8 \mathrm{mg} / \mathrm{d}$ \\
4 & Group IV & Probiotics alone & $1 \mathrm{~g} / \mathrm{d}$ \\
5 & Group V & 5-FU powder along with probiotics & $8 \mathrm{mg} / \mathrm{d}+\mathrm{I} \mathrm{g/d}$ \\
6 & Group VI & 5-FU-loaded nanoparticles along & $8 \mathrm{mg} / \mathrm{d}+\mathrm{I} \mathrm{g/d}$ \\
& & \\
\hline
\end{tabular}

Abbreviations: po, per oral route; GG, guar gum; XG, xanthan gum; 5-FU, 5-fluorouracil; S, serial; no, number; d, day.

At the end of the third hour, the media was degassed using carbon dioxide gas to remove undissolved oxygen and to maintain anaerobic conditions inside the medium for 15 minutes. Then, $4 \%$ (w/v) of rat cecal content (from different treated groups) was added to the dissolution media, and the study was continued for up to 24 hours under the continuous purging of $\mathrm{CO}_{2}$ throughout the study. The $1.0 \mathrm{~mL}$ samples were withdrawn at different time intervals from the dissolution medium and were replaced by the fresh medium that was maintained under anaerobic condition. The volume of the sample was made up to $10 \mathrm{~mL}$, filtered, and analyzed for 5-FU by ultraviolet spectroscopy at a wavelength of $265.6 \mathrm{~nm}$.

\section{In vivo evaluation}

The distribution and dosage schedule for animals per group are shown in Table 1.

The dosages were freshly prepared everyday by suspension in milk. They were administered by an oral gavage needle for the first and subsequent exposure for a duration of 5 days each, at an interval of 20 days.

\section{Diarrhea assessment}

All animals were assessed three times daily, and diarrhea was recorded per previous gradings. The fecal content from each group was examined daily in the early morning for the assessment of diarrhea. Recordings were completed and graded according to the grading procedure given by Gibson et al (Table 2). ${ }^{39}$

Table 2 The ranking of diarrhea

\begin{tabular}{ll}
\hline Rank & Type of diarrhea \\
\hline 0 & No diarrhea \\
1 & $\begin{array}{l}\text { Mild diarrhea (staining to anus) } \\
2\end{array}$ \\
$\begin{array}{l}\text { Moderate diarrhea (staining over top of the legs and lower } \\
\text { abdomen) }\end{array}$ \\
$\begin{array}{l}\text { Severe diarrhea (staining over legs and higher abdomen, } \\
\text { often with continual anal leakage) }\end{array}$ \\
\hline
\end{tabular}

Note: Data from Gibson et al. ${ }^{39}$ 


\section{Results and discussion}

\section{Evaluation of 5-FU-loaded nanoparticles} Morphology and particle size analysis

A smoother surface was obtained for the nanoparticles by using the emulsion solvent evaporation technique. As expected, the shape of the particles was found to be spherical. The photomicrographs of the prepared particles are shown in Figure 1.

As is well known, the size of a drug carrier plays a great role in controlling drug delivery to the target sites. So, when our study was carried out, the diameter of the particles was our top concern. The nanoparticles prepared in our study are appropriate for delivering the drug to the disease sites. Particle size analysis showed that nanoparticles were rather homogeneous in size with a range of $200 \pm 50 \mathrm{~nm}$.

\section{Drug-loading capacity and encapsulation efficiency} The drug loading for 5-FU in the nanoformulation was found to be $50 \%$ with an encapsulation efficiency of $95.4 \%$.

\section{In vitro drug release study}

The in vitro drug release study was carried out for 24 hours. The mean in vitro drug release showed that only $5 \%$ of the drug was released after 5 hours under simulated gastric and intestinal fluids. The percentage of drug released after a 6-hour wash increased (17\%) in the presence of cecal content. After 24 hours, the percentage of cumulative amount of 5-FU released in the presence of cecal content was found to be $93 \%$. It is evident from the results that the 5-FU-loaded nanoparticles were successful in retarding the initial drug release in other parts of the gastrointestinal tract except the colon as shown in Figure 2.

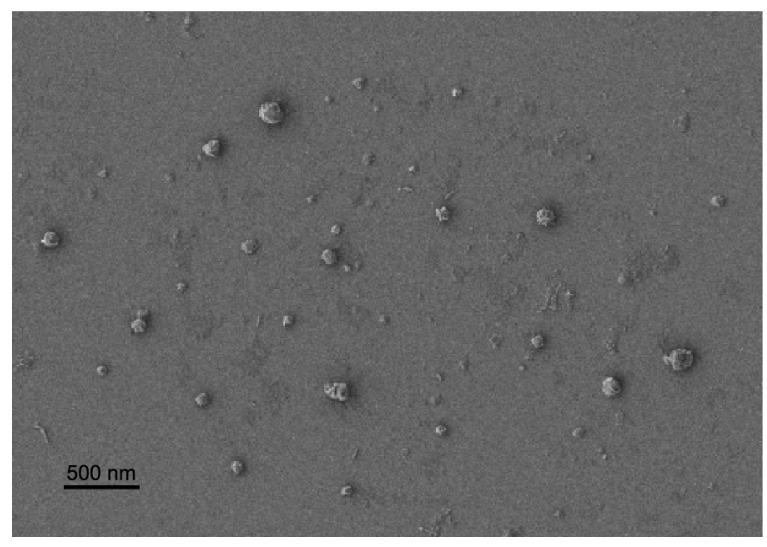

Figure I SEM image of 5-FU-loaded nanoparticles. Abbreviations: SEM, scanning electron microscopy; 5-FU, 5-fluorouracil.

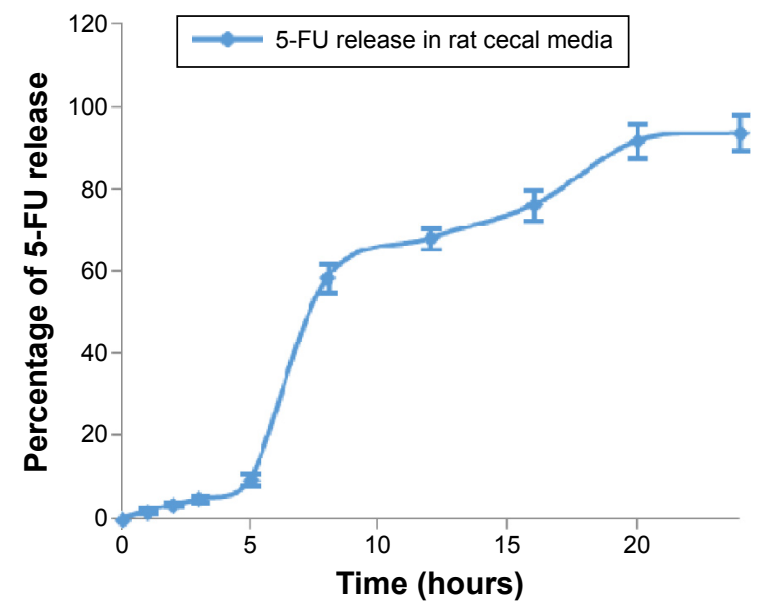

Figure 2 Mean percentage of 5-fluorouracil released from nanoformulations (all values are mean $\pm S E M ; n=3$ ).

Abbreviations: SEM, standard error of the mean; 5-FU, 5-fluorouracil.

\section{In vivo evaluation}

Preclinical symptoms

No changes were observed in the behavior of the animals during the treatment duration. Also, there was no death among the experimental animals assigned to the repeated treatment exposure.

\section{Body weight}

This study determined the mean body weight of animals exposed to the different treatments. There was a gain in body weight observed in animals exposed to nanoparticles of GG and XG (17.68\% weight increment) and probiotics treatment (25.74\%), when compared with the initial weights of their respective group after the 30th day of treatment. 5-FU powder alone and 5-FU nanoparticles at doses of $8 \mathrm{mg} / \mathrm{d}$ per oral route (po) for the duration of 5 days of repeated exposure showed a reduction in body weight of $32.73 \%$ and $17.09 \%$, respectively, whereas an increase in body weight $(4.01 \%$ and $3.86 \%$ ) was observed when 5 -FU powder $(8 \mathrm{mg} / \mathrm{d}$ po) was administered along with probiotics $(1 \mathrm{~g} / \mathrm{d}$ po) on repeated exposure. The reduction in body weight was less in animals exposed to nanoparticles of 5-FU $(7.26 \%$ and $8.69 \%)$ when compared with animals exposed to the 5-FU powder. The percentage increase in body weight was $5.84 \%$ and $3.33 \%$ in animals exposed to nanoparticles of 5 -FU $(8 \mathrm{mg} / \mathrm{d} \mathrm{po})$ along with probiotics $(1 \mathrm{~g} / \mathrm{d}$ po $)$ after the first and second exposures, respectively, for a duration of 5 days, and the results are shown in Table 3.

\section{Diarrhea assessment}

All animals were assessed three times daily, and diarrhea was recorded per previous gradings. Severe diarrhea was 
Table 3 Change in body weight of animals

\begin{tabular}{|c|c|c|c|c|c|c|}
\hline \multirow{2}{*}{$\begin{array}{l}\text { Groups } \\
\text { Group I }\end{array}$} & \multicolumn{2}{|c|}{ Zeroth and sixth days (g) } & \multicolumn{2}{|c|}{ Sixth and 26th days (g) } & \multicolumn{2}{|c|}{ 26th and 32nd days (g) } \\
\hline & $238.6 \pm 2.22$ & $255.2 \pm 2.99(t$-value $=4.45)$ & $259.6 \pm 2.18$ & $279.8 \pm 6.78(t$-value $=2.83)$ & $259.6 \pm 3.78$ & $279.8 \pm 6.78(t$-value $=2.83)$ \\
\hline Group II & $244.4 \pm 3.38$ & $164.4 \pm 5.58(t$-value $=8.95)$ & $165.9 \pm 9.76$ & $243.6 \pm 16.73(t-$ value $=4.04)$ & $243.6 \pm 16.73$ & $202.4 \pm 14.42(t$-value $=1.89)$ \\
\hline Group III & $258.6 \pm 2.18$ & $279.8 \pm 6.78(t$-value $=2.83)$ & $208.9 \pm 2.85$ & $284.6 \pm 8.66(t$-value $=8.30)$ & $284.6 \pm 8.66$ & $259.9 \pm 10.19(t$-value $=1.85)$ \\
\hline Group IV & $230.2 \pm 4.88$ & $252.6 \pm 6.84(t$-value $=2.66)$ & $247.3 \pm 10.13$ & $297.3 \pm 32.27(t$-value $=1.48)$ & $297.3 \pm 32.27$ & $3|0.1 \pm 36.1|(t$-value $=0.26)$ \\
\hline Group V & $229.6 \pm 4.42$ & $239.2 \pm 1.49(t$-value $=2.06)$ & $239.3 \pm 2.72$ & $257.3 \pm 7.21(t$-value $=2.33)$ & $257.3 \pm 7.21$ & $257.6 \pm 6.74(t$-value $=0.03)$ \\
\hline Group VI & $235.2 \pm 4.84$ & $249.8 \pm 5.66(t$-value $=1.96)$ & $248.3 \pm 9.33$ & $299 \pm 3.53(t$-value $=I .50)$ & $299.7 \pm 32.53$ & $302.3 \pm 32.37(t$-value $=0.07)$ \\
\hline
\end{tabular}

Notes: All values are mean \pm SEM; $\mathrm{n}=3$. Group treatment details: Group I: nanoparticles of GG:XG 8 mg/d; Group II: 5-FU powder 8 mg/d; Group III: 5-FU-loaded nanoparticles $8 \mathrm{mg} / \mathrm{d}$; Group IV: probiotics alone I g/d; Group V: 5-FU powder along with probiotics 8 mg/d +I g/d; and Group Vl: 5-FU-loaded nanoparticles along with probiotics $8 \mathrm{mg} / \mathrm{d}+\mathrm{l} \mathrm{g} / \mathrm{d}$.

Abbreviations: 5-FU, 5-fluorouracil; d, day; GG, guar gum; XG, xanthan gum; SEM, standard error of the mean.

observed in the rats treated with 5-FU powder, and moderate diarrhea was observed in the rats treated with 5-FU-loaded nanoparticles. But no incidence of diarrhea was observed in the others groups. Assessment data are shown in Table 4.

\section{Change in the cecum contents}

Rats in the control group did not show any changes in cecum content. Bloody diarrhea was observed in the case of 5-FUtreated rats. Water consistency and mucous were observed in the case of 5-FU nanoparticle-treated rats. But, in the case of rats treated with probiotics along with the drug, the consistency of water was not observed (Figure 3).

\section{Histopathological changes}

Light micrographs of the middle colon suggested that pathological changes were seen among the different groups due to the different treatments given. A microscopy study suggested that the muscular and serosal layers appeared within normal limits. Results showed intact colonic mucosa with an intact epithelial lining of nanoparticles of GG and XG for the treated rats (Figure 4A). Diffuse ulceration of the colonic mucosa with a loss of a lining epithelium was observed for the case of 5-FU powder-treated rats (Figure 4B). But focal ulceration of the colonic mucosa with an intact lining epithelium was observed for the 5-FU nanoparticle-treated rats (Figure 4C).

Table 4 Ranking of diarrhea by treatment group

\begin{tabular}{ll}
\hline Groups & Ranking given \\
\hline Group I & 0 \\
Group II & 3 \\
Group III & 2 \\
Group IV & 0 \\
Group V & 0 \\
Group VI & 0 \\
\hline
\end{tabular}

Notes: Group treatment details: Group I: nanoparticles of GG:XG $8 \mathrm{mg} / \mathrm{d}$; Group II: 5-FU powder $8 \mathrm{mg} / \mathrm{d}$; Group III: 5-FU-loaded nanoparticles $8 \mathrm{mg} / \mathrm{d}$; Group IV: probiotics alone I g/d; Group V: 5-FU powder along with probiotics $8 \mathrm{mg} / \mathrm{d}+\mathrm{I}$ g/d; and Group Vl: 5 -FU-loaded nanoparticles along with probiotics $8 \mathrm{mg} / \mathrm{d}+\mid \mathrm{g} / \mathrm{d}$.

Abbreviations: 5-FU, 5-fluorouracil; d, day; GG, guar gum; XG, xanthan gum.
The mucosal layer was infiltrated by mononuclear inflammatory cells predominantly comprising lymphocytes and histiocytes for the case of the probiotic-treated rats (Figure 4D).

The submucosal, muscular, and serosal layers appear within normal limits for the probiotics and 5-FU-treated rats (Figure 4E). Figure 4F shows intact colonic mucosa with an intact epithelial lining for the animals treated with probiotics along with 5-FU nanoparticles.

\section{Comparative dissolution study of 5-FU- loaded nanoparticles in cecum contents of different treatment groups}

In vitro drug release profiles of the 5-FU-loaded nanoparticles in cecum from the different treatment groups are shown in Figure 5. This study revealed that the 5-FU release rate had a tendency to accelerate in the presence of cecum content for the probiotic-treated groups compared to the other groups.

\section{Conclusion}

5-FU is a chemotherapeutic agent given for the treatment of most cancers. A number of literature studies are available where the delivery of 5-FU to the colon causes serious systemic side effects, such as mucositis, diarrhea, alteration in normal microflora structure, and translocation of bacteria. So, a certain manipulation of human microflora is needed in the colon for maintaining the number of beneficial bacteria. This problem of alteration in normal microflora structure was overcome for the first time in this study by concomitant administration of 5-FU nanoparticles along with probiotics. The following conclusions can thus be made:

1. 5-FU considerably damages the microflora involved in the release of drugs from the "natural gum-based" delivery systems. Cecal contents of rats fed on 5-FU powder or 5-FU nanoparticles did not contain sufficiently active microbes. This was proven by the fact that when natural gum-based drug delivery systems (compression-coated 

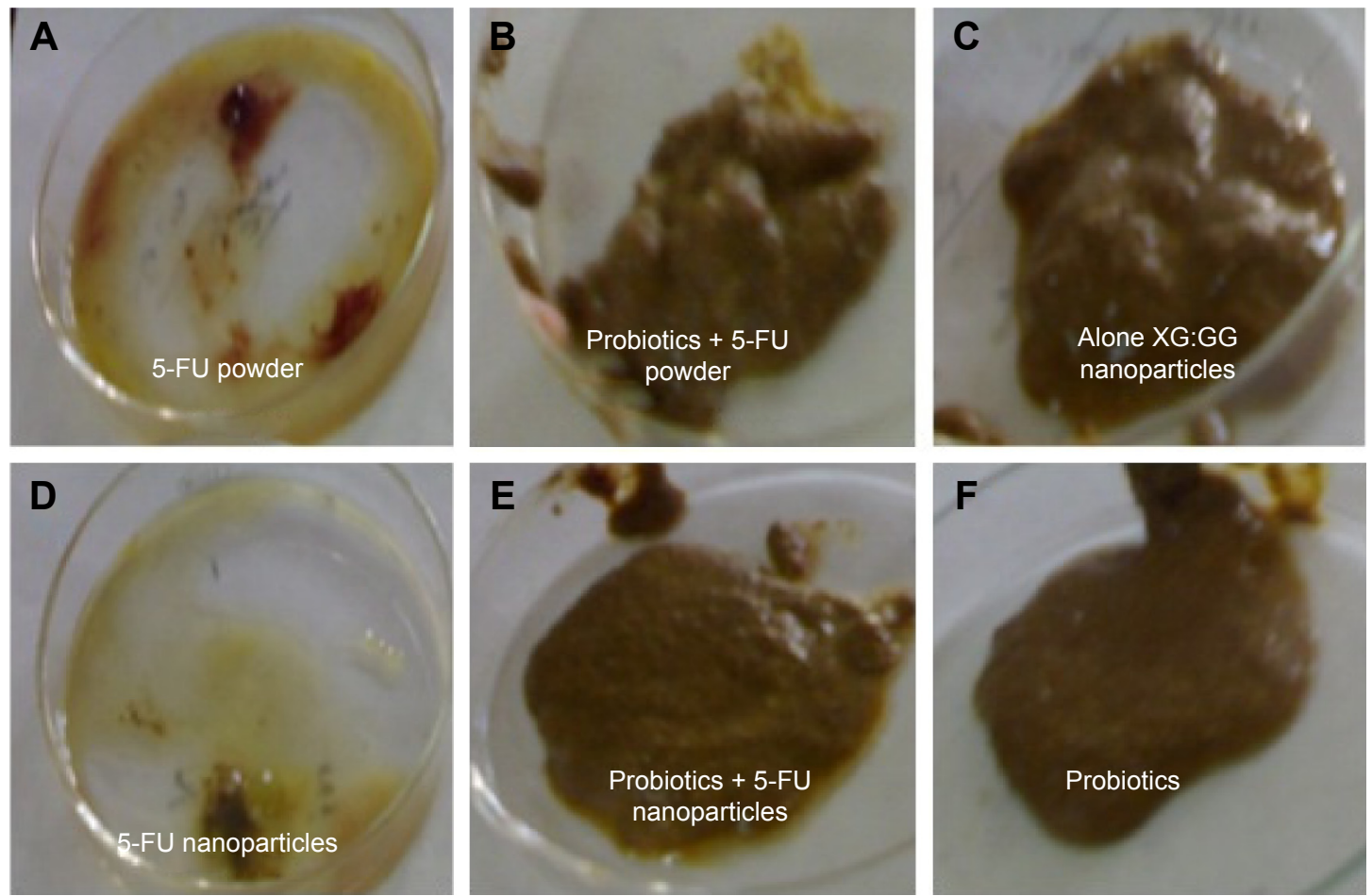

Figure 3 Examination of cecum content of different groups of rats after treatment.

Notes: (A) 5-FU powder, (B) probiotics + 5-FU powder, (C) XG:GG nanoparticles, (D) 5-FU nanoparticles, (E) probiotics + 5-FU nanoparticles, and (F) probiotics. Abbreviations: 5-FU, 5-fluorouracil; XG, xanthan gum; GG, guar gum.

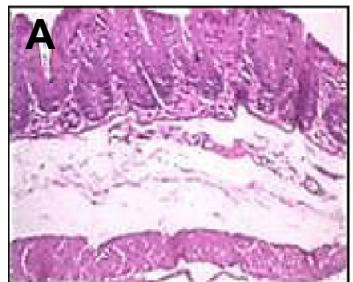

(H\&E stain 50x)

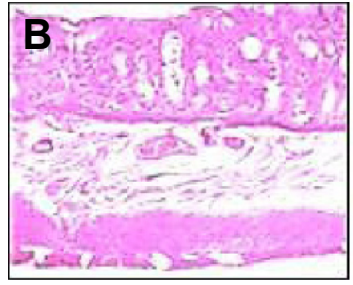

(H\&E stain 50x)

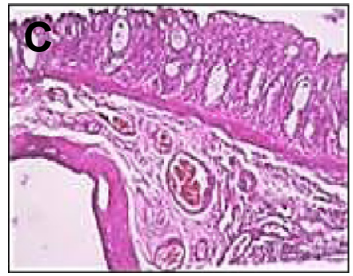

(H\&E stain 50x)

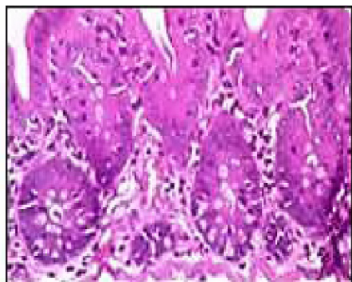

(H\&E stain 400x)

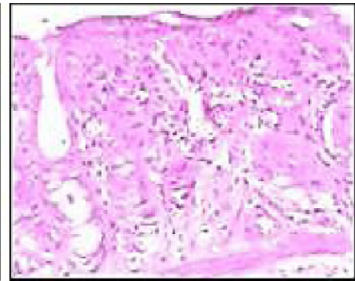

(H\&E stain 400x)

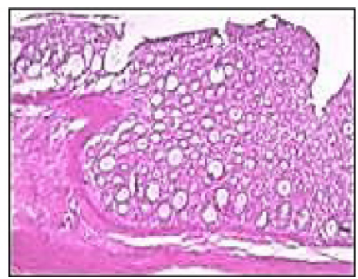

(H\&E stain 400x)

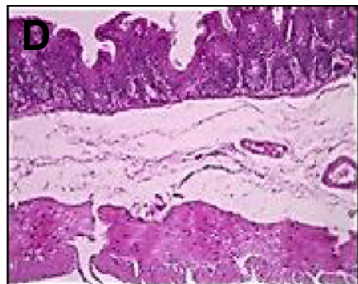

(H\&E stain 50x)

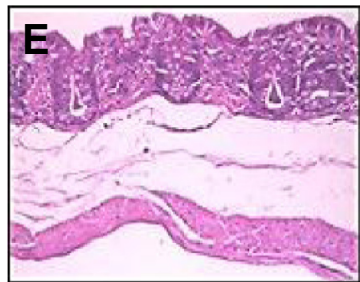

(H\&E stain 50x)

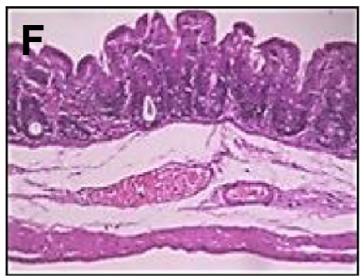

(H\&E stain 50x)

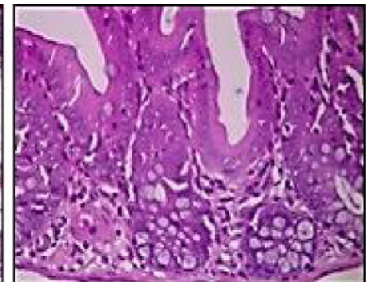

(H\&E stain 400x)

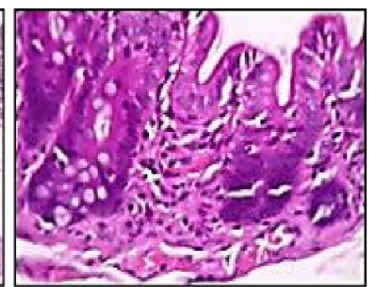

(H\&E stain 400x)

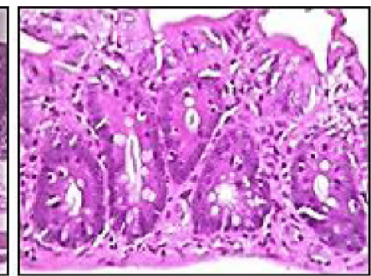

(H\&E stain 400x)

Figure 4 Histological features of colons after 30 days treatment

Notes: (A) Nanoparticles of XG:GG, (B) 5-FU powder, (C) 5-FU nanoparticles, (D) probiotics, (E) probiotics + 5-FU powder, and (F) probiotics + 5-FU nanoparticles.

Abbreviations: XG, xanthan gum; GG, guar gum; 5-FU, 5-fluorouracil; H\&E, hematoxylin and eosin. 


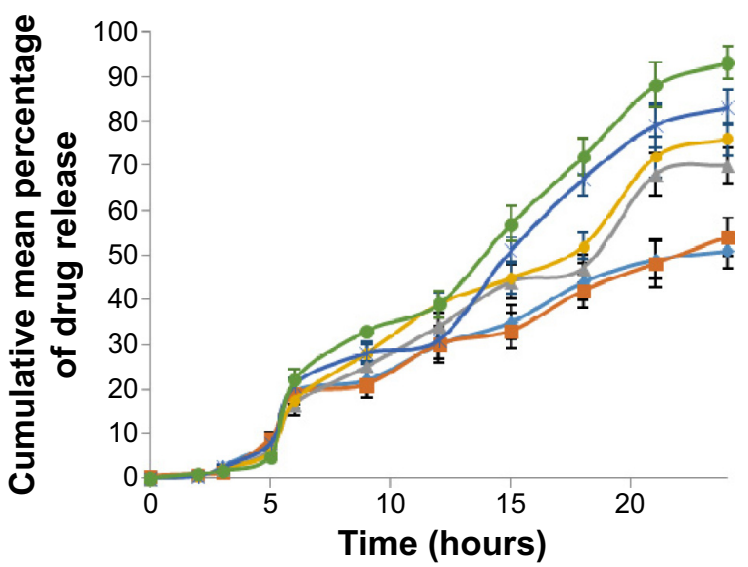

$\longrightarrow$ 5-FU powder $\quad-$ Probiotics +5 -FU nanoparticles
-5 -FU nanoparticles $\rightarrow$ XG:GG nanoparticles
- Probiotic +5 -FU $\rightarrow$ Probiotics

Figure 5 Dissolution study of 5-FU-loaded nanoparticles in cecum contents from the different treatment groups (all values are mean $\pm S E M ; n=3$ ).

Notes: All values are mean \pm SEM; $n=3$.

Abbreviations: XG, xanthan gum; GG, guar gum; 5-FU, 5-fluorouracil; SEM, standard error of the mean.

tablets/microspheres/nanoparticles) were exposed to the cecal contents of such rats, drug release was drastically reduced, ranging from $41 \%$ to $54 \%$ compared to $83 \%-92 \%$ for the control in which rats were not given any drug orally. This indicated that "microflora" in rats fed orally with 5-FU had been "damaged" because it is these microflora (bacteria) that are involved in digesting the natural gums in the "targeted drug delivery systems".

2. Administration of 5-FU in the form of nanoparticles coated with natural gums leads to a dual advantage. They allow for the release of the drug only in the colon. Moreover, they serve as food for the probiotics and allow the normal colonic bacteria to thrive.

3. The addition of probiotics had a "replenishing" effect on colonic microflora that had been damaged/lost due to "chemical attack" of the drug. A commercially available powdered form of Bifidobacterium species was coadministered along with nanoformulations of 5-FU to test animals (Albino Wister rats). A dose of $1 \mathrm{~g}$ of probiotics was coadministered per animal per day along with 5 -FU nanoparticles at a dose of $8 \mathrm{mg} / \mathrm{animal} / \mathrm{d}$. This was done to confirm whether the negative side effects on the gut microflora by nanoparticles of 5-FU could be overcomed by the coadministration of probiotics.

In vivo studies showed marked changes in cecum content in the different treatment groups. The consistency of cecal was much less in rats treated with 5-FU powder and 5-FU nanoparticles, but cecum content was found to be normal in the case of the others. From the histopathological study, diffuse ulceration and focal ulcerations were observed in 5-FU powder- and 5-FU nanoparticle-treated rats. Other groups in which concomitant administration of probiotics was complete showed intact colonic mucosa with an intact epithelial lining.

Henceforward, this study can be considered as a new report that focuses on the problem of the cytotoxicity of 5-FU toward colonic bacteria involved in the digestion of gums utilized for colon targeting. The study also offers a solution to the problem in terms of concomitant administration of probiotics along with colon-targeted 5-FU. This approach offers the advantage of minimizing the other gastrointestinal-related side effects, such as diarrhea, ulceration, and mucositis. A desirable formulation characteristic of 5-FU-loaded nanoparticles of GG and XG was achieved in terms of morphological characteristics, particle size analysis, encapsulation efficiency, and in vitro drug release.

\section{Disclosure}

Sima Singh declares that this work was from her MS dissertation work, supported by Lovely Professional University, Punjab, India, and that she filed a Patent Cooperation Treaty application with application numbers WO2012035561A2 and EP2632902 A2. The other authors report no conflicts of interest in this work.

\section{References}

1. Boyle P, Langman JS. ABC of colorectal cancer: epidemiology. BMJ. 2000;321:805-808.

2. Fauci AS, Braunwald E, Kaspe DL, Hauser LS, Longo DA, Jameson JL, editors. Gastrointestinal cancer. Harrison's Principles of Internal Medicine. 17th ed. New York: Mc Graw Hill; 2008.

3. Fauci AS, Braunwald E, Kaspe DL, Hauser LS, Longo DA, Jameson JL, editors. Oncology and hematology. Harrison's Principles of Internal Medicine. 17th ed. New York: Mc Graw Hill; 2008.

4. Elizabeth W, Jamel A. International trends in colorectal cancer incidence in rate. Cancer Epidemiol Biomarkers Prev. 2009;18:1688-1692.

5. Lieberman HA, Lachman L, Schwartz JB. Sustained Drug Release from Tablets and Particles Through Coating, Pharmaceutical Dosage Forms: Tablets. New York: Marcel Dekker Inc; 2005.

6. Kotla NG, Monica Gulati SK, Singh S, Shivapooja A. Facts, fallacies and future of dissolution testing of polysaccharide based colon specific drug delivery. J Control Release. 2014;178:55-62.

7. Friend DR. New oral delivery systems for treatment of inflammatory bowel disease. Adv Drug Deliv Rev. 2005;57:247-265.

8. Sathiyasekaran M, Shivbalan S. Crohn's disease. Ind J Pediatric. 2006; 78:723-729.

9. Garrett M, Kiddel RH, Winans CS. Treatment of chronic ulcerative colitis with poly-ASA: A new nonabsorbable carrier for release of 5-aminosalicylate in the colon. Gastrogenterol. 1983;84:1162-1163.

10. Kelly JP, Kaufman DW, Jurgelon JM. Risk of aspirin associated major upper gastrointestinal bleeding with enteric coated or buffered product. Lancet. 1996;348:1413-1416.

11. Banoob DW, McCloskey WW, Webster W. Risk of gastric injury with enteric versus non-enteric coated aspirin. Ann Pharmacother. 2002;36: $163-166$. 
12. Sibilia J, Ravaud P, Merck G. Digestive and hemorrhage complications of low dose of aspirin. Press Med. 2003;32:17-28.

13. Van den Mooter G, Maris B, Samyn C, Augustijns P, Kinget R. Use of azo polymers for colon-specific drug delivery. J Pharm Sci. 1997; $86: 1321-1327$.

14. Sinha VR, Kumria R. Colonic drug delivery: prodrug approach. Pharm Res. 2001;18:557-564.

15. Davis SS, Hardy JG, Fara JW. Transit of pharmaceutical dosage forms through the small intestine. Gut. 1986;27:886-892.

16. Chourasia MK, Jain SK. Pharmaceutical approaches to colon targeted drug delivery systems. J Pharm Sci. 2003;6:33-66.

17. Scheline RR. Metabolism of foreign compounds by gastrointestinal microorganisms. Pharmacol Rev. 1973;25:451-523.

18. Hovgaard L, Brondsted H. Current applications of polysaccharides in colon targeting. Crit Rev Ther Drug Carrier Syst. 1996;13:185-223.

19. Sinha VR, Kumria R. Review: polysaccharides in colon-specific drug delivery. Int J Pharm. 2001;224:19-38.

20. Sinha VR, Kumria R. Microbially triggered drug delivery to the colon. Eur J Pharm Sci. 2003;18:3-18.

21. Krishnaiah YSR, Satyanarayan S, Rama Prasad YV, Narasimha Rao S. Gamma scientigraphic studies on guar-gum matrix tablets for colonic drug delivery in healthy subjects. J Control Release. 1998;55: $245-252$.

22. Brown JP, McGarraugh GV, Parkinson TM, Wingard RE, Onderdonk AB. A polymeric drug for treatment of inflammatory bowel disease. J Med Chem. 1983;26:1300-1307.

23. Bayomi SM, Al-badr AA. 5-Fluorouracil. In: Florey K, editor. Analytical Profiles of Drug Substances. Vol 18. New York: Academic Press; 1989:599-627.

24. Lockhart PB, Sonis ST. Alterations in the oral mucosa caused by chemotherapeutic agents. A histologic study. J Dermatol Surg Oncol. 1981;7:1019-1025.

25. Mahood DJ, Dose AM, Loprinzi CL. Inhibition of 5-fluorouracil-induced mucositis by oral cryotherapy. J Clin Oncol. 1991;9:449-452.

26. Pico JL, vila-Garavito AA, Naccache P. Mucositis: its occurance, consequences, and treatment in the oncology setting. Oncologist. 1998; 3:446-451.

27. Viele CS. Overview of chemotherapy induced diarrhea. Semin Oncol Nurs. 2003;3:2-5.
28. Fauci AS, Braunwald E, Kasper DL, Hauser LS, Longo DA, Jameson JL, editors. Gastrointestinal cancer. Harrison's Principles of Internal Medicine. Vol 1. ed. 17th ed. New York: Mc Graw Hill; 2008:573-580.

29. Gutheli JC, Kearns CM, editors. Gastrointestinal complication of chemotherapy in M.C. The Chemotherapy Source Book. Vol 1. Ed. 4th ed. Philadelphia, PA, USA: Lippincott Williams \& Wilkins; 2008:197-208.

30. Mainous MR, Tso P, Berg RD, Deitch EA. Studies of the route, magnitude, and time course of bacterial translocation in a model of systemic inflammation. Arch Surg. 1991;126:33-37.

31. Berg RD. Mechanism confining indigenous bacteria to the gastrointestinal tract. Am J Clin Nutr. 1980;33:2472-2484.

32. Cerci C, Ergin C, Eroglu E, et al. Effects of granulocyte-colony stimulating factor on peritoneal defense mechanisms and bacterial translocation after administration of systemic chemotherapy in rats. World J Gastroenterol. 2007;13:2596-2599.

33. Kinget R, Kalala W, Vervoort L, Mooter GV. Colonic drug targeting. J Drug Target. 1998;6:129-149.

34. Sinha VR, Singh A, Singh S, Bhinge JR. Compression coated systems for colonic delivery of 5-fluorouracil. J Pharm Pharmacol. 2007;59: 359-365.

35. Krishnaiah YSR, Srinivas BP. Effects of 5-fluorouracil pretreatment on the in vitro drug release from colon-targeted guar-gum matrix tablets. Open Drug Delivery J. 2008;2:71-76.

36. Krishnaiah YSR, Karthikeyan RS. In vitro drug release studies on guar gum-based colon targeted oral drug delivery systems of 5-fluorouracil. Eur J Pharm Sci. 2002;16:185-192.

37. Chourasia MK, Jain SK, Soni V, Gupta Y. Crosslinked guar-gum microsphere: a viable approach for improved delivery of anticancer drugs for the treatment of colorectal cancer. AAPS PharmSciTech. 2006;7:44-52.

38. Kaushik D, Sardana S, Mishra DN. In vitro cytotoxicity analysis of 5 -fluorouracil loaded guar gum microspheres on HT-29 colon cancer cell line. Int J Pharm Sci Drug Res. 2009;1:83-84.

39. Gibson RJ, Bowen JM, Keefe DMK. Palifermin reduces diarrhea and increases survival following Irinotecan treatment in tumor-bearing DA rats. Int J Cancer. 2005;116:464-470.
International Journal of Nanomedicine

\section{Publish your work in this journal}

The International Journal of Nanomedicine is an international, peerreviewed journal focusing on the application of nanotechnology in diagnostics, therapeutics, and drug delivery systems throughout the biomedical field. This journal is indexed on PubMed Central, MedLine, CAS, SciSearch $\AA$, Current Contents $\AA /$ Clinical Medicine,

\section{Dovepress}

Journal Citation Reports/Science Edition, EMBase, Scopus and the Elsevier Bibliographic databases. The manuscript management system is completely online and includes a very quick and fair peer-review system, which is all easy to use. Visit http://www.dovepress.com/ testimonials.php to read real quotes from published authors. 